University of Nebraska - Lincoln

DigitalCommons@University of Nebraska - Lincoln

Faculty Publications, Department of Psychology

Psychology, Department of

October 2007

\title{
Acculturation, gender, and alcohol use among Mexican American college students
}

\author{
Marcela Raffaelli \\ University of Nebraska-Lincoln, mraffaelli1@unl.edu \\ Rosalie A. Torres Stone \\ University of Nebraska-Lincoln \\ Maria I. Iturbide \\ University of Nebraska-Lincoln \\ Meredith McGinley \\ University of Nebraska-Lincoln \\ Gustavo Carlo \\ University of Nebraska-Lincoln, carlog@missouri.edu \\ See next page for additional authors
}

Follow this and additional works at: https://digitalcommons.unl.edu/psychfacpub

Part of the Psychiatry and Psychology Commons

Raffaelli, Marcela; Torres Stone, Rosalie A.; Iturbide, Maria I.; McGinley, Meredith; Carlo, Gustavo; and Crockett, Lisa J., "Acculturation, gender, and alcohol use among Mexican American college students" (2007). Faculty Publications, Department of Psychology. 316.

https://digitalcommons.unl.edu/psychfacpub/316

This Article is brought to you for free and open access by the Psychology, Department of at DigitalCommons@University of Nebraska - Lincoln. It has been accepted for inclusion in Faculty Publications, Department of Psychology by an authorized administrator of DigitalCommons@University of Nebraska - Lincoln. 


\section{Authors}

Marcela Raffaelli, Rosalie A. Torres Stone, Maria I. Iturbide, Meredith McGinley, Gustavo Carlo, and Lisa J. Crockett 
Published in Addictive Behaviors 32:10 (October 2007), pp. 2187-2199; doi 10.1016/j.addbeh.2007.02.014

Copyright $\odot 2007$ Elsevier Ltd. Used by permission. http://www.sciencedirect.com/science/journal/03064603

Published online March 7, 2007.

\title{
Acculturation, gender, and alcohol use among Mexican American college students
}

\author{
Marcela Raffaelli, ${ }^{*}$ Rosalie A. Torres Stone, ${ }^{\dagger}$ Maria I. Iturbide, ${ }^{\ddagger}$ \\ Meredith McGinley, $\ddagger$ Gustavo Carlo, $\ddagger$ and Lisa J. Crockett $\ddagger$
}

* Department of Psychology and Institute for Ethnic Studies, 238 Burnett Hall, University of Nebraska-Lincoln, Lincoln, NE 68588-0308

${ }^{\dagger}$ Department of Sociology, 703 Oldfather Hall, University of Nebraska-Lincoln, Lincoln, NE 68588-0324

$\ddagger$ Department of Psychology, 238 Burnett Hall, University of Nebraska-Lincoln, Lincoln, NE 68588-0308

$\S$ Corresponding author-tel 402 472-0737; fax: 402 472-4637

\begin{abstract}
Email addresses: mraffaelli1@unl.edu (M. Raffaelli); rstone2@unl.edu (R. A. Torres Stone); miturbi1@bigred.unl.edu (M. I. Iturbide); meredithmcginley@gmail.com (M. McGinley); gcarlo1@unl.edu (G. Carlo); ecrockett1@unl.edu (L.J. Crockett).
\end{abstract}

\begin{abstract}
Prior research with non-college samples of Mexican Americans has demonstrated that gender moderates the association between acculturation and alcohol use. We replicated this finding in a college student sample and attempted to account for the differential impact of acculturation on Mexican American men and women by examining the mediating effects of social context, family conflict and psychological functioning. Participants were 148 Mexican Americans (67\% female; $M$ age 23 years) from three state universities in California and Texas who completed self-report surveys. In multivariate analyses controlling for age, maternal education, living situation, and site, linguistic acculturation was associated with increased alcohol use and misuse among women but not men. Two social context variables (social facilitation and family drinking) mediated the association between acculturation and alcohol use (heavy drinking, past year alcohol use, and a composite drinking variable) among women. The findings highlight the importance of social context for understanding alcohol use by Latina college students and indicate directions for future research and intervention development.
\end{abstract}

Keywords: acculturation, alcohol use, Mexican Americans, gender, social context, college students 


\section{Introduction}

U.S. college students are more likely than young adults who are not attending college to use and abuse alcohol (O'Malley and Johnston, 2002; Windle, 2003). Alcohol misuse is associated with substantial morbidity and mortality among college students (Hingson, Heeren, Zakocs, Kopstein, and Wechsler, 2002), including those who do not drink (Wechsler, Moeykens, Davenport, Castillo, and Hansen, 1995). As a result, college students have been identified as a priority population for alcohol interventions (National Institute on Alcohol Abuse and Alcoholism, 2002), and efforts have been made to identify factors linked to alcohol use and misuse by college students (see Baer, 2002; Presley et al., 2002).

Latino college students are more likely than African Americans, but less likely than European Americans, to use and misuse alcohol (O'Malley and Johnston, 2002; Windle, 2003), and more likely than either group to report a lifetime diagnosis of alcohol abuse or dependence (Clements, 1999). Latinos are the fastest growing ethnic group in the U.S. (Ramirez and de la Cruz, 2003) and their presence on college campuses is also increasing (American Council on Education, 2005). To date, however, research on college student drinking has failed to take into account the growing numbers of Latinos on college campuses (Dowdall and Wechsler, 2002; Hatchett and Holmes, 2004). The current study was designed to address this gap.

\subsection{Factors related to alcohol use in Latino populations}

One factor linked to alcohol use among Latinos is acculturation, the process of psychological and behavioral adaptation that occurs when two cultures come into contact. Multiple studies conducted primarily with non-college populations indicate that "acculturation is positively associated with alcohol consumption, especially among women" (Caetano and Clark, 2003, p. 225), whereas acculturation is less strongly related to alcohol use among Latino men (see also Alaniz et al., 1999; Marín and Posner, 1995). The differential association is attributed to the fact that norms regulating women's alcohol use are stricter in Latin America than in the U.S., whereas norms regulating alcohol use by men tend to be liberal in both Latin America and the U.S. (Caetano and Clark, 2003; Gilbert and Collins, 1997).

Few published studies have investigated how acculturation affects alcohol use among Latino college students. In contrast to most studies of adults, a recent study of heavy drinking among Mexican American college students did not find a gender by acculturation effect (Zamboanga, Raffaelli, and Horton, 2006). Thus, our first goal was to investigate the moderating role of gender on multiple indicators of alcohol use in a different sample. Our second goal was to identify factors that might account for the association between acculturation and alcohol use.

\subsection{Acculturation, gender, and alcohol use: potential intervening factors}

Among non-Latino college students, drinking patterns vary by social context. For example, college students who drank for social facilitation (e.g., with friends, at bars) were more likely to be high-intensity drinkers than those who drank in family contexts (Beck, Thombs, Mahoney, and Fingar, 1995; see also Ichiyama and Kruse, 2002). Moreover, highly acculturated Latinos "are more likely to frequent social settings where alcohol is consumed ... and to drink in these situations" (Caetano and Clark, 2003, p. 224; see Caetano, 1987; Gilbert and Collins, 1997). Thus, we speculated that social context factors might account for the acculturation-alcohol use relation. 
Family conflict is associated with substance use (Hawkins, Catalano, and Miller, 1992) and may be particularly problematic for Latinos, who typically place a high value on harmonious family relationships (Marín and Marín, 1991). In a recent study of Mexican American adolescents, family conflict mediated associations between acculturation and substance use (McQueen, Getz, and Bray, 2003). Other research indicates that conflict in Latino families may be associated with acculturation-related issues (Vega and Gil, 1999). Expectations in Latino families differ for daughters and sons (Raffaelli and Ontai, 2004); thus, Latinas who delay marriage to study and prepare for a career may experience heightened conflict with parents. We considered both general conflict and conflict specifically linked to acculturation as potential mediators.

Finally, we considered psychological functioning. Depressive symptoms and low self-esteem are associated with alcohol use among college students (see Baer, 2002, for review). Psychological well-being has been linked to acculturation in Latino populations, although the direction of association is inconclusive (see Balls Organista, Organista, and Kurasaki, 2003). Large-scale epidemiological studies have found positive associations between acculturation and depression among Mexican Americans (e.g., Kaplan and Marks, 1990), but acculturation was positively associated with self-esteem in a study of Latino college students (Valentine, 2001).

In summary, the current study was designed to examine whether gender moderates the association between acculturation and alcohol use among Mexican American college students, and to explore whether social context, family conflict, and psychological functioning mediate that association. We focused on Mexican Americans because Latino subgroups differ on multiple dimensions, including alcohol use (e.g., Marín and Posner, 1995). Mexican Americans account for two thirds of all U.S. Latinos (Ramirez and de la Cruz, 2003); thus, there is a clear need to examine factors associated with their health and well-being.

\section{Method}

\subsection{Participants and procedure}

The study was conducted at three state universities (one in Texas, two in California). Data were collected during the summer in Texas and the academic year in California. The university in Texas had approximately 2300 students, nearly half of whom were Hispanic. One of the California universities had approximately 16,000 undergraduate students, about one quarter Hispanics; the other was larger (25,000 undergraduates) and was less than $20 \%$ Hispanic. At all three sites, student volunteers from psychology courses provided written informed consent before completing self-report surveys in small groups.

The current analysis was restricted to individuals of Mexican or Mexican American origin or descent. The analytic sample consisted of 148 18-30 year old students (67\% female; see Table 1 for sample characteristics). Most ( $84 \%$ ) had been born in the U.S., but over half had one (26\%) or two (46\%) nonU.S.-born parents.

\subsection{Measures}

Participants completed demographic questions and multi-item scales. Unless otherwise specified, scale scores were computed by averaging and respondents must have answered at least $75 \%$ of the items to receive a score. 
Table 1. Descriptive statistics for study variables

\begin{tabular}{|c|c|c|c|}
\hline Variable (possible range) & Males $(n=49)$ & Females $(n=99)$ & Total $(N=148)$ \\
\hline Age in years (18-30) & $23.24(3.73)$ & $22.95(3.13)$ & $23.05(3.33)$ \\
\hline Maternal education (1-7) & $2.41(1.56)$ & $2.34(1.36)$ & $2.36(1.42)$ \\
\hline Acculturative status $(1-5)$ & $3.24(1.10)$ & $3.44(1.09)$ & $3.37(1.10)$ \\
\hline \multicolumn{4}{|l|}{ Alcohol use } \\
\hline Past year alcohol use (1-4) & $1.94(1.18)$ & $1.46(0.95)^{*}$ & $1.62(1.05)$ \\
\hline Past month alcohol use (1-4) & 1.59 (1.17) & $1.09(0.96)^{*}$ & $1.26(1.06)$ \\
\hline Binge drinking (1-5) & $1.67(1.49)$ & $.78(1.23)^{* * *}$ & $1.07(1.38)$ \\
\hline Drinking composite & $1.73(1.17)$ & $1.10(0.89)^{* * *}$ & $1.31(1.03)$ \\
\hline \multicolumn{4}{|l|}{ Drinking contexts } \\
\hline Social Facilitation (1-5) & $2.83(1.25)$ & $2.55(1.10)$ & $2.64(1.13)$ \\
\hline Family (1-5) & $1.95(.96)$ & $1.74(.87)$ & $1.81(0.90)$ \\
\hline \multicolumn{4}{|l|}{ Family conflict } \\
\hline Conflict with parent $(1-5)$ & $2.03(0.99)$ & $1.88(0.80)$ & $1.93(0.87)$ \\
\hline Family stress (1-5) & $2.32(.90)$ & $2.40(0.93)$ & $2.38(0.92)$ \\
\hline \multicolumn{4}{|l|}{ Psychological functioning } \\
\hline Depression (0-3) & $1.32(.62)$ & $1.28(.55)$ & $1.29(0.57)$ \\
\hline Self-esteem (1-4) & $3.27(.53)$ & $3.32(.50)$ & $3.31(0.51)$ \\
\hline Live on own (\% yes) & $36.7 \%$ & $56.6 \%$ * & $50 \%$ \\
\hline Texas site (\%) & $67.3 \%$ & $49.5 \%$ * & $55.4 \%$ \\
\hline
\end{tabular}

Note. Unless otherwise indicated, values are means (standard deviations). Results of gender comparisons (one way ANOVAs and chi-square with continuity correction): ${ }^{*} p<.05 .{ }^{* *} p<.01 .{ }^{* * *} p<.001$.

\subsubsection{Demographic and control variables}

Age (SAMHSA, 2000), living situation (Baer, 2002), and socioeconomic status (Hawkins et al., 1992) are each associated with alcohol use and were included as control variables. In addition, preliminary analyses revealed significant differences between the Texas site and one or both California sites on demographic variables (age, gender, maternal education, living situation) and on Social Facilitation and Family Stress (but not on acculturative status or alcohol use).

Respondents indicated their gender $(0=$ female, $1=$ male) and age (in years). Mother's educational attainment was reported on a scale from $1=$ elementary/junior high to $7=$ professional or graduate degree; 32\% had not completed high school, $29 \%$ had a high school diploma, and 39\% had at least some post-secondary education. Living situation was coded as $1=$ live with parents $(50 \%)$ or 2 = live on own (50\%; in an apartment or house [39.2\%], dorm [4.1\%], Greek house [1.4\%] or other [5.4\%]). Site was coded as 1 = Texas, 2 = California.

\subsubsection{Acculturative status}

A modified version of the 5-item Language Use factor of the Short Acculturation Scale for Hispanics (SASH; Marín, Sabogal, Marín, Otero-Sabogal, and Perez-Stable, 1987) was administered. One item ("In general, what language do read and speak?") was divided into two, resulting in a 6-item measure of linguistic acculturation. Respondents rated the degree to which they used their native language and/or English on a 5-point scale ( 1 = native language only, $5=$ English only) in different situations. Cronbach's alpha for the 6 -item scale was high $(\alpha=.93)$ and comparable to the original measure $(\alpha=.90$; Marín et al., 1987). 


\subsubsection{Alcohol use}

Three aspects of drinking were assessed. Participants rated their frequency of drinking beer/wine/ wine coolers/champagne during the past year on a 6-point scale from never to every day. Because few students reported drinking more than once a week (i.e., levels 5-6 on the scale), responses were recorded into four levels: never (19.3\%), once or twice (23.4\%), 1-3 times a month (33.1\%), and at least once a week (24.1\%). Frequency of drinking beer/wine/wine coolers/champagne during the past 30 days was assessed on a 7-point scale from never to over a hundred times; because few students reported drinking on 20 or more occasions (i.e., levels 5-7), responses were recorded into four levels: never (30.8\%), once or twice $(28.0 \%), 3-9$ times $(25.9 \%), 10$ or more times $(15.4 \%)$. The third item assessed number of heavy drinking episodes ( 5 or more drinks in one sitting) during the past 30 days on a 5-point scale: none $(52.8 \%)$, one $(16.2 \%), 2-3$ times $(12.0 \%), 4-5$ times $(9.2 \%), 6$ or more times $(9.9 \%)$. These three variables were examined separately; in addition, a composite was created by averaging $(\alpha=.84)$.

\subsubsection{Drinking contexts}

The measure included items similar to the Social Facilitation and Family Drinking subscales on the college version of the Social Context of Drinking Scale (Beck et al., 1995), rated on a 5-point scale from never to always. Five items $(\alpha=.89)$ reflected Social Facilitation (drinking with friends, at bars/sports bars/clubs, at parties, during sporting events, and during social functions). Two items $(\alpha=.81)$ assessed Family Drinking (with family members and at family gatherings); respondents must have answered one item to receive a score on this scale.

\subsubsection{Family conflict}

Participants completed the Parent Conflict subscale from the Network of Relationships Inventory (Furman and Buhrmester, 1992). Three items (e.g., "How much do you and your parent get upset or mad with each other?") were rated on a 5-point scale from little or none to the most $(\alpha=.89)$. They also completed the 3-item Family Stress subscale (Fuertes and Westbrook, 1996) from the Social, Attitudinal, Familial and Environmental Acculturative Stress Scale (Mena, Padilla, and Maldonaldo, 1987). Each item (e.g., "close family members and I have conflicting expectations about my future") was rated a 5 -point scale from not stressful to very stressful $(\alpha=.63)$. For each scale, respondents must have answered at least two items to receive a score.

\subsubsection{Psychological functioning}

Two widely used measures of psychological functioning were administered. The Center for Epidemiological Studies-Depression Scale (CES-D; Radloff, 1977) assesses frequency of 20 depressive symptoms during the past week using a 4-point scale from rarely or none of the time to most or all of the time. Reliability in our sample was high $(\alpha=.90)$. The Rosenberg Self Esteem Scale (Rosenberg, 1979) consists of 10 items (e.g., "I feel that I have a number of good qualities") rated on a 4-point scale from strongly disagree to strongly agree $(\alpha=.85)$.

\section{Data analytic approach}

Main analyses involved a set of multiple linear regressions to test the association between acculturation and each of the four alcohol use variables, and to determine whether gender moderated that association. Control variables (age, maternal education, living situation, and site), gender, and acculturative status were entered in the first step of each model. The interaction between acculturative status (centered) and gender was entered in the second step. 


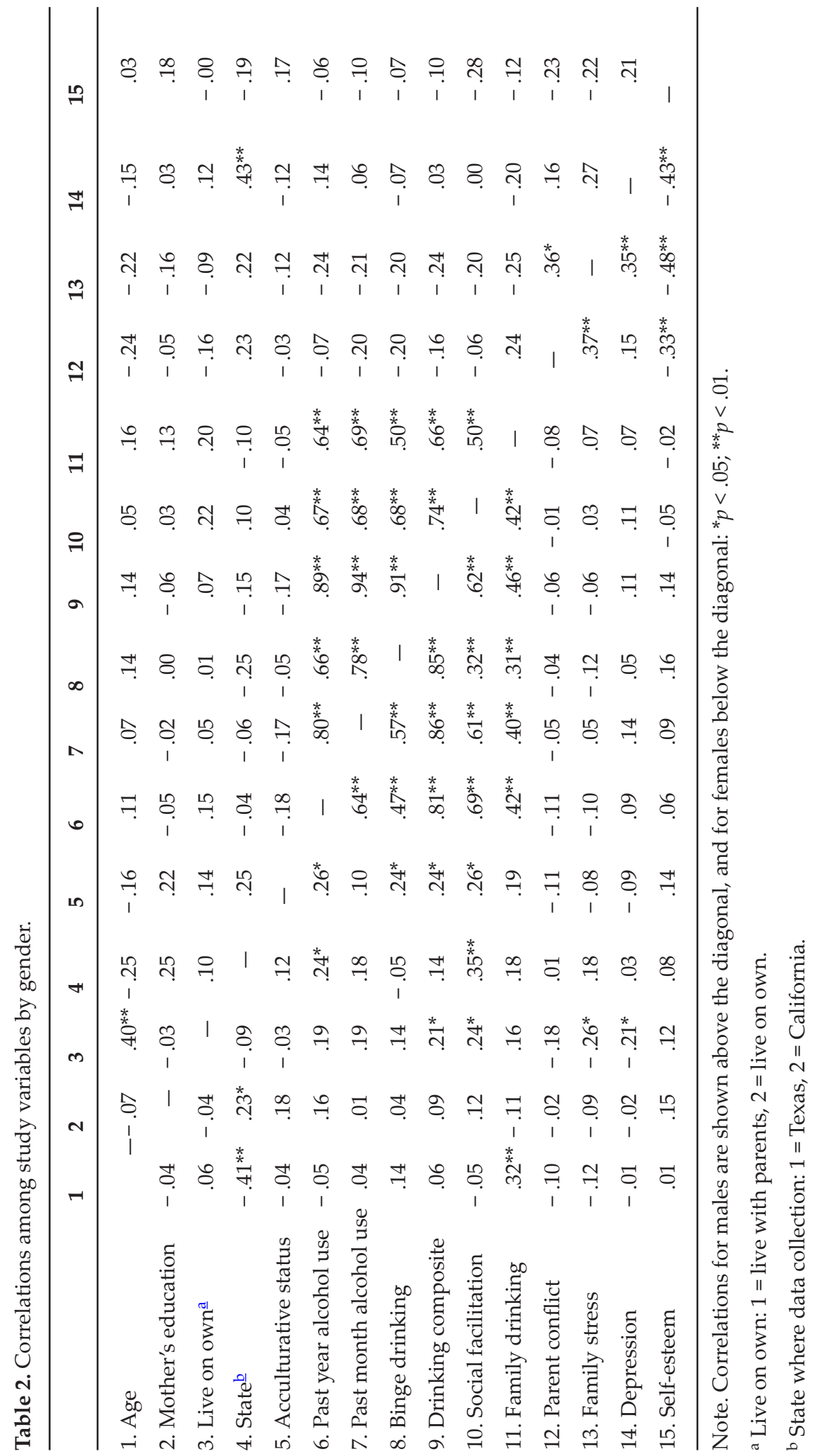


We next examined whether drinking contexts, family conflict, and psychological functioning mediated the relation between acculturation and alcohol use for either gender. Following Baron and Kenny (1986), a set of multiple linear regression models was computed for each outcome variable and hypothesized mediator. The first model included controls and acculturative status to establish that acculturation was significantly associated with the outcome. A parallel model was computed to establish that acculturation was associated with the proposed mediator. The third model examined whether the proposed mediator and outcome were significantly related, net of controls. If the predicted significant relations were found in these three models, a final regression model was computed with controls and acculturative status entered on the first step and the mediator on the second step. A drop in the coefficient for acculturative status on the second step can be interpreted as evidence of mediation (Baron and Kenny, 1986). The Sobel test was used to evaluate whether the mediated effect was significant).

\section{Results}

\subsection{Descriptive analyses}

Descriptive statistics and gender comparisons for all study variables are displayed in Table 1. Fewer men lived on their own and were from California, but there were no gender differences in age, maternal education, acculturative status, or the proposed mediators. Male respondents reported more alcohol use than their female peers.

Table 3. Linear regressions examining impact of gender and acculturation on alcohol use.

\begin{tabular}{|c|c|c|c|c|c|c|c|c|c|c|c|c|}
\hline & \multicolumn{3}{|c|}{ Last month alcohol use } & \multicolumn{3}{|c|}{ Last year alcohol use } & \multicolumn{3}{|c|}{ Binge drinking } & \multicolumn{3}{|c|}{ Drink composite } \\
\hline & $B$ & $S E B$ & Beta & $B$ & SE B & Beta & $B$ & $S E B$ & Beta & $B$ & $S E B$ & Beta \\
\hline \multicolumn{13}{|l|}{ Step one variables } \\
\hline Age & 0.01 & 0.03 & .02 & 0.00 & 0.03 & -.01 & 0.03 & 0.04 & .08 & 0.15 & 0.03 & .05 \\
\hline Maternal education & -0.01 & 0.06 & -.02 & 0.03 & 0.06 & .04 & 0.23 & 0.08 & .23 & 0.01 & 0.06 & .01 \\
\hline State ${ }^{\mathrm{a}}$ & 0.25 & 0.20 & .12 & 0.28 & 0.19 & .14 & -0.30 & 0.25 & -.11 & 0.10 & 0.19 & .05 \\
\hline Live on own ${ }^{b}$ & 0.30 & 0.19 & .14 & 0.44 & 0.18 & $.21^{*}$ & 0.22 & 0.23 & .08 & 0.34 & 0.17 & $.17+$ \\
\hline \multicolumn{13}{|l|}{ Step two variables } \\
\hline Gender ${ }^{\mathrm{c}}$ & 0.54 & 0.20 & $.24^{* *}$ & 0.52 & 0.19 & $.24^{* *}$ & 0.81 & 0.25 & $.28^{* *}$ & 0.62 & 0.18 & $.29^{* *}$ \\
\hline Acculturative status & 0.10 & 0.10 & .10 & 0.24 & 0.10 & $.25^{*}$ & 0.31 & 0.13 & $.25^{*}$ & 0.22 & 0.09 & $.24^{*}$ \\
\hline \multicolumn{13}{|l|}{ Step three variables } \\
\hline Gender $\times$ acculturatior & $\mathrm{n}-0.31$ & 0.17 & $-.19+$ & -0.51 & 0.16 & $-.32^{* *}$ & -0.37 & 0.22 & $-.17+$ & -0.43 & 0.16 & $-.27^{* *}$ \\
\hline \multicolumn{13}{|c|}{ Step and model statistics } \\
\hline Step one & \multicolumn{3}{|c|}{$R^{2}=.010, F=.33$} & \multicolumn{3}{|c|}{$R^{2}=.027, F=0.94$} & \multicolumn{3}{|c|}{$R^{2}=.037, F=1.24$} & \multicolumn{3}{|c|}{$R^{2}=.013, F=.43$} \\
\hline Step two & \multicolumn{3}{|c|}{$\Delta R^{2}=.056, \Delta F=3.91^{*}$} & \multicolumn{3}{|c|}{$\Delta R=.058, \Delta F=4.15^{*}$} & \multicolumn{3}{|c|}{$\Delta R=.092, \Delta F=6.78^{* *}$} & \multicolumn{3}{|c|}{$\Delta R=.085, \Delta F=6.26^{* *}$} \\
\hline Step three & \multicolumn{3}{|c|}{$\Delta R^{2}=.024, \Delta F=3.33+$} & \multicolumn{3}{|c|}{$\Delta R=.064, \Delta F=9.87^{* *}$} & \multicolumn{3}{|c|}{$\Delta R=.018, \Delta F=2.74+$} & \multicolumn{3}{|c|}{$\Delta R=.046, \Delta F=7.11^{*}$} \\
\hline Model & \multicolumn{3}{|c|}{$R^{2}=.090, F=1.81+$} & \multicolumn{3}{|c|}{$R^{2}=.149, F=3.28^{* *}$} & \multicolumn{3}{|c|}{$R^{2}=.146, F=3.14^{* *}$} & \multicolumn{3}{|c|}{$R^{2}=.144, F=3.17^{* *}$} \\
\hline
\end{tabular}

Note. Regression coefficients are from the final model. $+p<.10 ;{ }^{*} p<.05 ;{ }^{* *} p<.01 ;{ }^{* * *} p<.001$.

a 1 = Texas, 2 = California.

b $1=$ With parents, $2=$ On own.

${ }^{\mathrm{c}} 0=$ Female, $1=$ Male. 

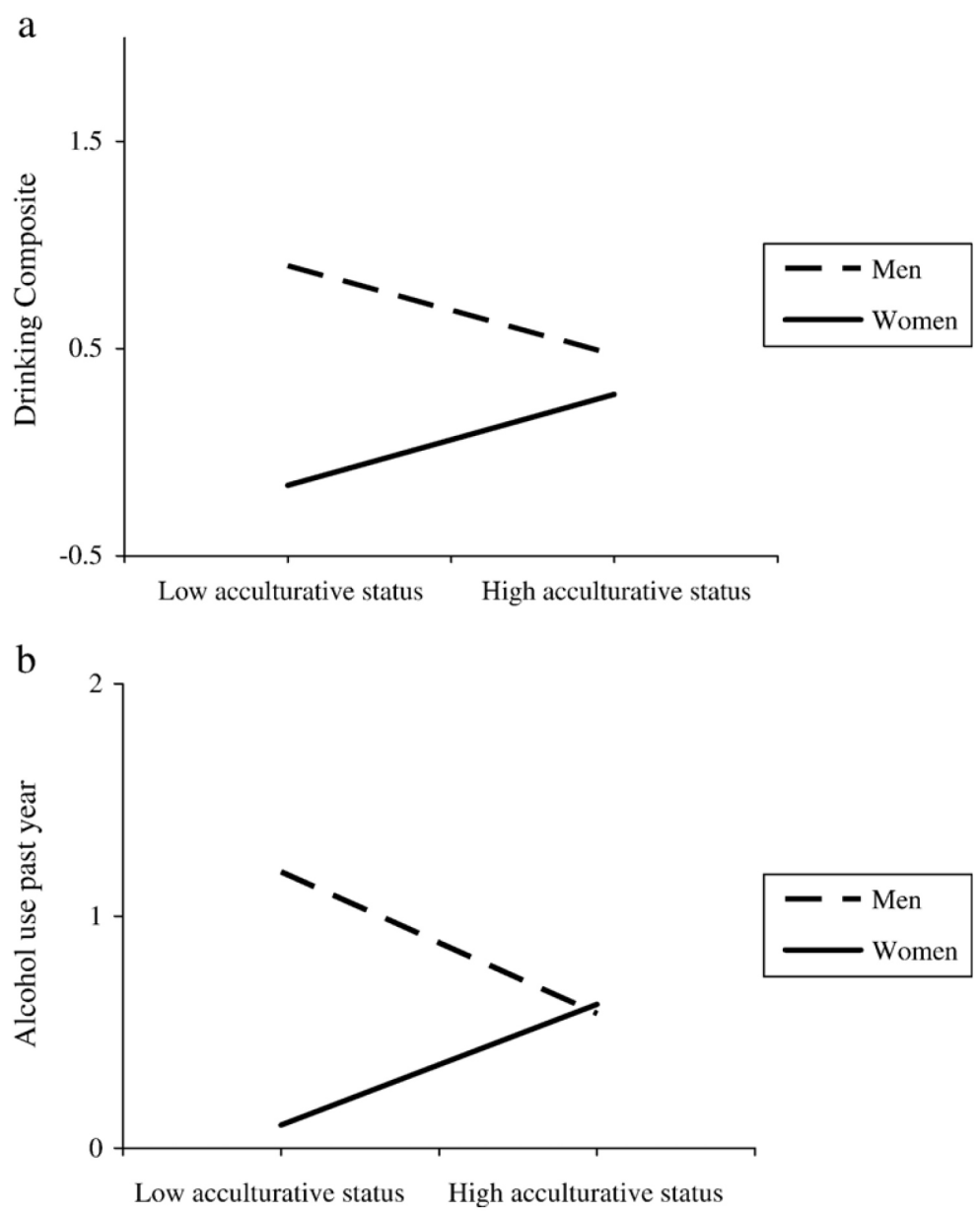

Figure 1. (a.) Plot of the interaction between gender and acculturation on alcohol use (drinking composite). (b.) Plot of the interaction between gender and acculturation on alcohol use in the past year.

Bivariate correlations are shown in Table 2. Of greatest relevance to the current study, acculturative status was not associated with men's alcohol use, but was significantly and positively correlated with women's past year alcohol use, binge drinking, and the composite drinking variable. Of the six proposed mediators, the two social context variables (Social Facilitation and Family Drinking) were associated with alcohol use for both genders.

\subsection{Moderating role of gender}

The moderating effect of gender was examined following the strategy described in the Analytic Plan. Table 3 displays final model coefficients and step and model statistics. The interaction term coefficient was significant in two models (alcohol use in the last year and the composite drinking variable). To interpret the significant interactions, the value of each outcome variable was plotted as a function of gen- 
der and acculturative status. In both cases, there was a positive association between acculturation and alcohol use for women, whereas men showed the opposite pattern (Figure 1).

\subsection{Potential mediators of the association between acculturation and alcohol use}

In regressions examining mediating relations, acculturative status was not independently associated with any of the four drinking variables among men; thus, the first criterion for mediation was not met and no further analyses were conducted. Among women, acculturative status was associated with binge drinking, past year alcohol use, and the drinking composite. In addition, the two social context variables were each independently associated with acculturative status and the same three drinking variables, meeting criteria for mediation; the two family conflict and two psychological functioning variables were not associated with either acculturative status or alcohol use and were not considered further (results not shown).

Table 4 depicts results of analyses examining whether Social Facilitation mediated the relation between acculturation and alcohol use among women. The regression coefficient for acculturative status was significant at the first step of each regression, but dropped to non-significance at the second step, when Social Facilitation was entered. The indirect effect was significant for past year alcohol use $(z=2.44, p<.05)$ and the drinking composite $(z=2.39, p<.05)$, and marginally significant for binge drinking $(z=1.86, p=.06)$. A similar pattern of results emerged in parallel analyses for Family Drinking (Table 5), and the indirect effect was marginally significant for past year alcohol use $(z=1.90, p=.06)$,

Table 4. Regression models examining whether social facilitation mediates between acculturation and alcohol use among women.

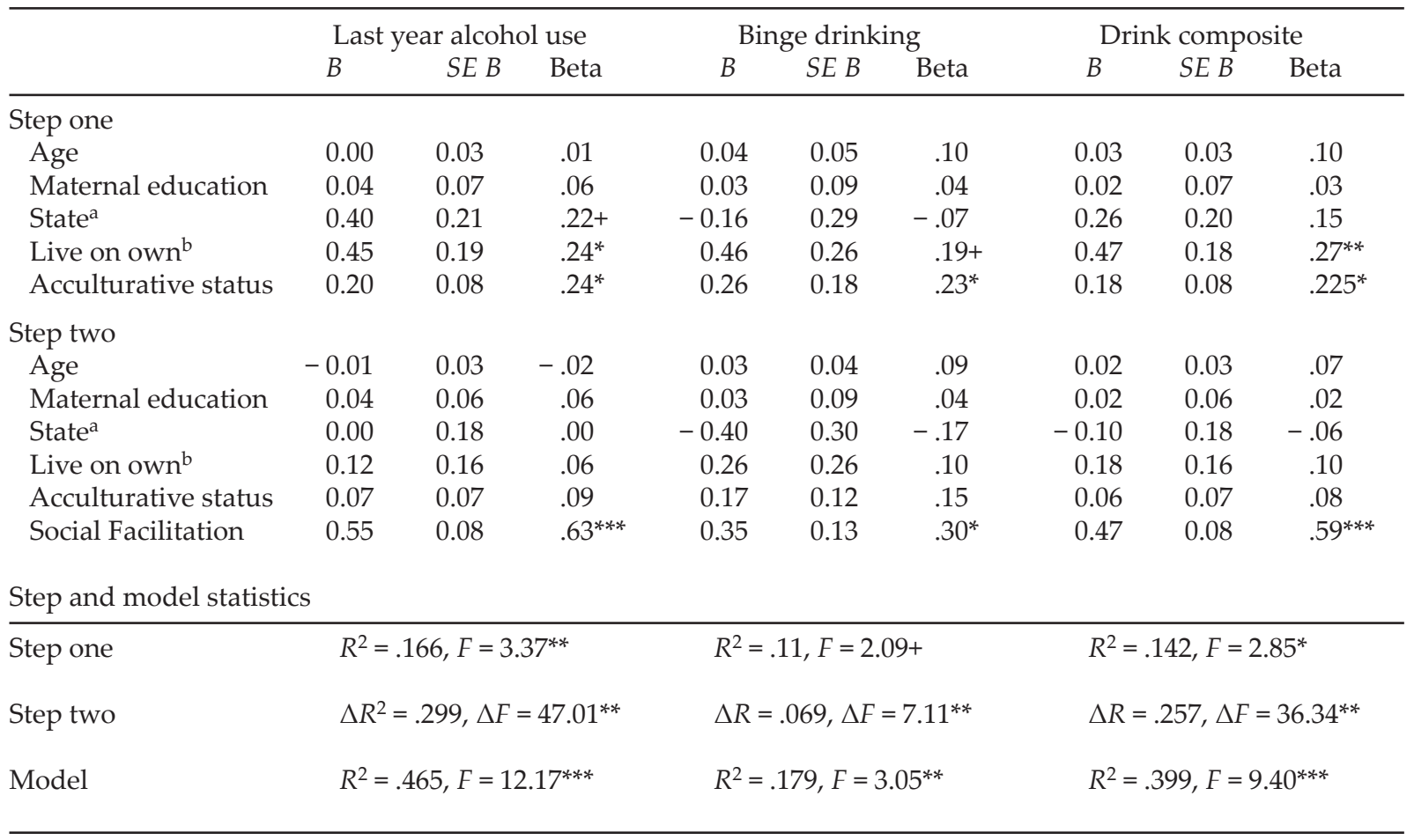

Note. $+p<.10 ;{ }^{*} p<.05 ;{ }^{* *} p<.01 ;{ }^{* * *} p<.001$.

a 1 = Texas, 2 = California. 
Table 5. Regression models examining whether family drinking mediates between acculturation and alcohol use among women

\begin{tabular}{|c|c|c|c|c|c|c|c|c|c|}
\hline \multirow{3}{*}{$\overline{\text { Step one }}$} & \multicolumn{3}{|c|}{ Last year alcohol use } & \multicolumn{3}{|c|}{ Binge drinking } & \multicolumn{3}{|c|}{ Drink composite } \\
\hline & \multirow[t]{2}{*}{$B$} & \multirow[t]{2}{*}{ SE B } & \multirow[t]{2}{*}{ Beta } & \multirow{2}{*}{$B$} & \multirow[t]{2}{*}{$S E B$} & \multirow[t]{2}{*}{ Beta } & \multirow[t]{2}{*}{$B$} & \multirow[t]{2}{*}{$S E B$} & \multirow[t]{2}{*}{ Beta } \\
\hline & & & & & & & & & \\
\hline Age & 0.00 & 0.03 & .01 & 0.04 & 0.05 & .10 & 0.03 & 0.03 & .10 \\
\hline Maternal education & 0.04 & 0.07 & .07 & 0.05 & 0.09 & .05 & 0.02 & 0.07 & .04 \\
\hline State ${ }^{a}$ & 0.39 & 0.22 & $.21+$ & -0.20 & 0.29 & -.08 & 0.24 & 0.20 & .14 \\
\hline Live on own ${ }^{b}$ & 0.44 & 0.19 & $.23^{*}$ & 0.43 & 0.26 & $.17+$ & 0.46 & 0.18 & $.26^{*}$ \\
\hline Acculturative status & 0.21 & 0.09 & $.24^{*}$ & 0.26 & 0.12 & $.24^{*}$ & 0.18 & 0.08 & $.23^{*}$ \\
\hline \multicolumn{10}{|l|}{ Step two } \\
\hline Age & -0.06 & 0.04 & -.20 & -0.02 & 0.05 & -.05 & -0.03 & 0.03 & -.12 \\
\hline Maternal education & 0.10 & 0.07 & .16 & 0.11 & 0.09 & .12 & 0.08 & 0.06 & .13 \\
\hline State $\mathrm{a}^{\mathrm{a}}$ & 0.05 & 0.22 & .03 & -0.53 & 0.31 & $-.22+$ & -0.10 & 0.20 & -.06 \\
\hline Live on own $\underline{\underline{b}}$ & 0.31 & 0.18 & $.17+$ & 0.31 & 0.25 & .13 & 0.33 & 0.16 & $.19^{*}$ \\
\hline Acculturative status & 0.13 & 0.08 & .16 & 0.19 & 0.12 & .17 & 0.11 & 0.08 & .14 \\
\hline Family drinking & 0.45 & 0.12 & $.42^{* * *}$ & 0.44 & 0.16 & $.32^{* *}$ & 0.45 & 0.11 & $.46^{* * *}$ \\
\hline \multicolumn{10}{|c|}{ Step and model statistics } \\
\hline Step one & \multicolumn{3}{|c|}{$R^{2}=.164, F=3.29^{* *}$} & \multicolumn{3}{|c|}{$R^{2}=.11, F=2.15+$} & \multicolumn{3}{|c|}{$R^{2}=.140, F=2.77^{*}$} \\
\hline Step two & \multicolumn{3}{|c|}{$\Delta R^{2}=.126, \Delta F=14.73^{* * *}$} & \multicolumn{3}{|c|}{$\Delta R=.071, \Delta F=7.27^{* *}$} & \multicolumn{3}{|c|}{$\Delta R=.144, \Delta F=16.85^{* * * *}$} \\
\hline Model & \multicolumn{3}{|c|}{$R^{2}=.290, F=5.65^{* * *}$} & \multicolumn{3}{|c|}{$R^{2}=.185, F=3.14^{* *}$} & \multicolumn{3}{|c|}{$R^{2}=.284, F=5.44^{* * *}$} \\
\hline
\end{tabular}

Note. $+p<.10 ;{ }^{*} p<.05 ;{ }^{* *} p<.01 ;{ }^{* * *} p<.001$.

${ }^{\text {a }} 1=$ Texas, $2=$ California.

b $1=$ With parents, $2=$ On own.

heavy drinking $(z=1.70, p=.09)$, and the drinking composite $(z=1.93, p=.053)$. Taken together, the results indicate that social context (particularly Social Facilitation) mediated the acculturation-alcohol use relation.

\section{Discussion}

The differential effect of acculturation on alcohol use among Latino men and women is well established, yet possible mechanisms for the differential association have not been identified. The current study builds on prior research by investigating the impact of linguistic acculturation on the alcohol use of Mexican American college students and examining factors that might account for gender differences in the relations between acculturation and alcohol use.

To our knowledge, only one other study has investigated the role of acculturation and gender in alcohol use among Latino college students (Zamboanga et al., 2006). In that study of Mexican American college students in the Midwest, there was no association between acculturation and heavy drinking for women. In contrast, we found that acculturation was associated with increased alcohol use (including binge drinking) among female Mexican American college students, which is consistent with findings from non-college samples (e.g., Alaniz et al., 1999; Caetano and Clark, 2003). The current study differed from Zamboanga et al.'s study in several ways, including location, sample characteristics, and measure of acculturation. It would be desirable to replicate the analyses in a nationally representative sample.

Scholars have noted that acculturation is associated with changing settings of alcohol use (e.g., Caetano, 1987; see Caetano and Clark, 2003), but to our knowledge this is the first study to conduct for- 
mal tests of mediation to evaluate the role of social contexts. Our findings support the notion that acculturation contributes indirectly to alcohol use by increasing women's involvement in settings where alcohol is consumed. It may be that Latina college students who are more acculturated associate with non-Latino peers who facilitate alcohol use. Future research that examines how the ethnic composition of college students' social networks is related to alcohol use could address this possibility. Contrary to research conducted in general populations, which indicates that family drinking is associated with less alcohol use among college students (Beck et al., 1995), in the current study both social context variables were associated with higher levels of alcohol use among Latinas. More detailed examination of patterns of alcohol use in Latino families is needed to elucidate this finding.

Contrary to expectations, there was no association between the other four potential mediators (depressive symptoms, self-esteem, family stress, parent conflict) and either acculturation or alcohol use. Prior research has linked these factors to alcohol use among non-Latino college students (Baer, 2002), and one study found that family conflict mediated between acculturation and substance use among Mexican American high school students (McQueen et al., 2003). Additional research is needed to replicate these findings and identify other mediators of the relation between acculturation and alcohol use among Latina college students.

\subsection{Limitations and future directions}

The study had several limitations that remain to be addressed. The lifetime and past month measures of alcohol use focused only on frequency of drinking, whereas scholars recommend assessing both frequency and quantity (e.g., Baer, 2002; Caetano and Clark, 2003). In addition, episodic heavy drinking was defined as five or more drinks in one sitting (the same definition used in many national studies of college student drinking; O'Malley and Johnston, 2002), rather than differentiating by gender (e.g., 5 or more drinks for men, 4 or more for women) or taking factors such as weight into account (Dowdall and Wechsler, 2002). Moreover, although language is a key indicator of acculturation (Marín and Marín, 1991) that is associated with alcohol use among Mexican American adults (Marín and Posner, 1995) and multiple types of substance use among Latino adolescents (McQueen et al., 2003), it does not directly index psychological aspects of cultural adaptation. It would be informative to replicate the study using other measures of alcohol use and a multidimensional measure of acculturation. Sample limitations should also be kept in mind. Participants were volunteers from three different institutions and participation rates are unknown, limiting the generalizability of findings to other student populations. It would be useful to replicate the study in a nationally representative sample and to examine whether the pattern of findings varies according to campus characteristics (Dowdall and Wechsler, 2002).

Notwithstanding these limitations, this study contributes novel information to the literature on acculturation, gender, and alcohol use. Most importantly, findings indicate that social context factors may explain the association between acculturation and alcohol use and misuse by female Mexican American college students. Given the potential negative consequences of alcohol use for female college students, including date rape and unwanted sexual advances (Abbey, 1991; Perkins, 2002; Wechsler et al., 1995), identifying ways to reduce unsafe drinking on college campuses represents an important public health priority.

\section{Acknowledgements}

Data collection was supported by grants to Marcela Raffaelli and Gustavo Carlo from the University of Nebraska-Lincoln's Office of the Research Council, Institute for Ethnic Studies, and Human Rights and 
Human Diversity Initiative. The authors thank Scott Roesch and Gabriel Holguien for facilitating data collection. Data analyses and manuscript preparation were supported by Nebraska Tobacco Settlement Biomedical Research Enhancement Funds.

\section{References}

Abbey, 1991: A. Abbey, Acquaintance rape and alcohol consumption on college campuses: How are they linked?, Journal of American College Health 39 (1991), pp. 165-169.

Alaniz et al., 1999: M. L. Alaniz, A. J. Treno, and R. F. Saltz, Gender, acculturation, and alcohol consumption among Mexican-Americans, Substance Use \& Misuse 34 (1999), pp. 1407-1426.

American Council on Education, 2005: American Council on Education, ACE Releases Its Annual Status Report on Minorities in Higher Education (2005, February 14) Retrieved 5/17/06 from http://www.acenet.edu/

Baer, 2002: J. S. Baer, Student factors: Understanding individual variation in college drinking [special issue], Journal of Studies on Alcohol 14 (2002), pp. 40-53.

Balls Organista et al., 2003: P. Balls Organista, K.C. Organista, and K. Kurasaki, The relationship between acculturation and ethnic minority mental health. In: K. M. Chun, P. B. Organista and G. Marín, Editors, Acculturation: Advances in theory, measurement, and applied research, American Psychological Association, Washington, DC (2003), pp. 139-161.

Baron and Kenny, 1986: R. M. Baron and D. A. Kenny, The moderator-mediator variable distinction in social psychological research: Conceptual, strategic, and statistical considerations, Journal of Personality and Social Psychology 51 (1986), pp. 1173-1182.

Beck et al., 1995: K. H. Beck, D. L. Thombs, C. A. Mahoney, and K. M. Fingar, Social context and sensation seeking: Gender differences in college student drinking motivations, International Journal of the Addictions 30 (1995), pp. $1101-1115$.

Caetano, 1987: R. Caetano, Acculturation, drinking, and social settings among U.S. Hispanics, Drug and Alcohol Dependence 19 (1987), pp. 215-226.

Caetano and Clark, 2003: R. Caetano and C. L. Clark, Acculturation, alcohol consumption, smoking, and drug use among Hispanics. In: K. M. Chun, P. B. Organista and G. Marín, Editors, Acculturation: Advances in theory, measurement, and applied research, APA, Washington, DC (2003), pp. 223-239.

Clements, 1999: R. Clements, Prevalence of alcohol-use disorders and alcohol-related problems in a college student sample, Journal of American College Health 48 (1999), pp. 111-118.

Dowdall and Wechsler, 2002: G. W. Dowdall and H. Wechsler, Studying college alcohol use: Widening the lens, sharpening the focus, Journal of Studies on Alcohol 14 (2002), pp. 14-22 (Supp.).

Fuertes and Westbrook, 1996: J. N. Fuertes and F. D. Westbrook, Using the Social, Attitudinal, Familial, and Environmental (SAFE) Acculturative Stress Scale to assess the adjustment needs of Hispanic college students, Measurement and Evaluation in Counseling and Development 29 (1996), pp. 67-76.

Furman and Buhrmester, 1992: W. Furman and D. Buhrmester, Age and sex differences in perceptions of networks of personal relationships, Child Development 63 (1992), pp. 103-115.

Gilbert and Collins, 1997: M. J. Gilbert and R. L. Collins, Ethnic variation in women's and men's drinking. In: R. W. Wilsnack and S. C. Wilsnack, Editors, Gender and alcohol: Individual and social perspectives, Rutgers Center of Alcohol Studies, Piscataway, NJ (1997), pp. 357-378.

Hatchett and Holmes, 2004: B. F. Hatchett and K. Y. Holmes, Attitudes of college students in a predominately Hispanic university regarding alcohol use, Journal of Ethnicity in Substance Abuse 3 (2004), pp. 25-41.

Hawkins et al., 1992: J. D. Hawkins, R. F. Catalano, and J. Y. Miller, Risk and protective factors for alcohol and other drug problems in adolescence and early adulthood: Implications for substance abuse prevention, Psychological Bulletin 112 (1992), pp. 64-105.

Hingson et al., 2002: R. W. Hingson, T. Heeren, R. C. Zakocs, A. Kopstein, and H. Wechsler, Magnitude of alcoholrelated mortality and morbidity among U.S. college students ages 18-24, Journal of Studies on Alcohol 63 (2002), pp. 136-144. 
Ichiyama and Kruse, 1998: M. A. Ichiyama and M. I. Kruse, The social contexts of binge drinking among private university freshmen, Journal of Alcohol and Drug Education 44 (1998), pp. 18-33.

Kaplan and Marks, 1990: M. S. Kaplan and G. Marks, Adverse effects of acculturation: Psychological distress among Mexican American young adults, Social Science \& Medicine 31 (1990), pp. 1313-1319.

Marín and Marín, 1991: G. Marín and B. V. Marín, Research with Hispanic populations, Sage, Newbury Park (1991).

Marín and Posner, 1995: G. Marín and S. F. Posner, The role of gender and acculturation on determining the consumption of alcoholic beverages among Mexican-Americans and Central Americans in the United States, International Journal of the Addictions 30 (1995), pp. 779-794.

Marín et al., 1987: G. Marín, G. Sabogal, B. V. Marín, R. Otero-Sabogal, and E. J. Perez-Stable, Development of a short acculturation scale for Hispanics, Hispanic Journal of Behavioral Sciences 9 (1987), pp. 183-205.

McQueen et al., 2003: A. McQueen, J. G. Getz, and J. H. Bray, Acculturation, substance use, and deviant behavior: Examining separation and family conflict as mediators, Child Development 74 (2003), pp. 1737-1750.

Mena et al., 1987: F. J. Mena, A. M. Padilla, and M. Maldonado, Acculturative stress and specific coping strategies among immigrant and later generation college students, Hispanic Journal of Behavioral Sciences 9 (1987), pp. 207-225.

National Institute on Alcohol Abuse and Alcoholism, 2002: National Institute on Alcohol Abuse and Alcoholism, Changing the culture of campus drinking, NIAAA Alcohol Alert 58 (2002) Retrieved 6/14/06 from http://pubs. niaaa.nih.gov

O'Malley and Johnston, 2002: P. M. O'Malley and L. D. Johnston, Epidemiology of alcohol and other drug use among American college students, Journal of Studies on Alcohol 14 (2002), pp. 23-39 (Supp.).

Perkins, 2002: H. W. Perkins, Social norms and the prevention of alcohol misuse in collegiate contexts, Journal of Studies on Alcohol 14 (2002), pp. 164-172 (Supp.).

Presley et al., 2002: C. A. Presley, P. W. Meilman, and J. S. Leichliter, College factors that influence drinking, Journal of Studies on Alcohol 14 (2002), pp. 82-90 (Supp.).

Radloff, 1977: L. S. Radloff, The CES-D scale: A self-report depression scale for research in the general population, Applied Psychological Measurement 1 (1977), pp. 385-401.

Raffaelli and Ontai, 2004: M. Raffaelli and L. L. Ontai, Gender socialization in Latino/a families: Results from two retrospective studies, Sex Roles: A Journal of Research 50 (2004), pp. 287-299.

Ramirez and de la Cruz, 2003: R. R. Ramirez and G. P. de la Cruz, The Hispanic population in the United States: March 2002 (2003) Retrieved 8/30/05 from http://www.census.gov/prod/2003pubs/p20-534.pdf

Rosenberg, 1979: M. Rosenberg, Conceiving the self, Basic Books, New York (1979).

SAMHSA, 2000: SAMHSA [Substance Abuse and Mental Health Services Administration], Summary findings from the 1999 National Household Survey on Drug Abuse, DHHS Publication No. (SMA)00-3466, SAMHSA, Rockville, MD (2000).

Valentine, 2001: S. Valentine, Self-esteem, cultural identity, and generation status as determinants of Hispanic acculturation, Hispanic Journal of Behavioral Sciences 23 (2001), pp. 459-468.

Vega and Gil, 1999: W. A. Vega and A. G. Gil, A model for explaining drug use behavior among Hispanic adolescents, Drugs and Society 14 (1999), pp. 57-74.

Wechsler et al., 1995: H. Wechsler, B. Moeykens, A. Davenport, S. Castillo, and J. Hansen, The adverse impact of heavy episodic drinkers on other college students, Journal of Studies on Alcohol 56 (1995), pp. 628-634.

Windle, 2003: M. Windle, Alcohol use among adolescents and young adults, Alcohol Research \& Health 27 (2003), pp. 79-85.

Zamboanga et al., 2006: B. L. Zamboanga, M. Raffaelli, and N. J. Horton, Acculturation status and heavy alcohol use among Mexican American college students: Investigating the moderating role of gender, Addictive Behaviors 31 (2006), pp. 2188-2198. 